\title{
A IMPORTÂNCIA DO PODER LOCAL PARA CONCRETIZAÇÃO DOS DIREITOS HUMANOS A PARTIR DO INSTRUMENTO DA POLÍTICA PÚBLICA DO ICMS ECOLÓGICO
}

\author{
Luiza Gaspar Feio ${ }^{1}$ \\ Lise Tupiassu ${ }^{2}$
}

RESUMO: A pesquisa apresenta o papel do Poder Local para efetivação dos Direitos Humanos com a finalidade de expor as transformações que ocorreram no federalismo brasileiro, a partir da consideração do Município como ente federativo e, assim, competente para atuar em seu território, mediante a necessidade da promoção do espaço sustentável, por meio da elaboração de suas próprias políticas governamentais através da verba pública derivada do repasse obrigatório da arrecadação do imposto estadual de circulação de mercadorias e serviços, a partir de critérios socioambientais da política pública do ICMS Ecológico.

Palavras-chave: Poder Local. Política Pública. Direitos Humanos. ICMS Ecológico. Verba Pública.

\section{THE IMPORTANCE OF LOCAL GOVERNMENT FOR THE CONCRETIZATION OF HUMAN RIGHTS STARTING FROM THE INSTRUMENT ECOLOGICAL}

\section{ICMS}

\begin{abstract}
The research presents the role of Local Government in guaranteeing Human Rights with the objective to expose the transformations that occurred in Brazilian federalism, starting with the recognition of the Municipality as a federative entity and, therefore, competent to act in its territory, through the necessity of promotion of sustainable spaces. This way, through the elaboration of local governmental policies and the mandatory transfer of state sales tax revenue, mechanisms are being studied to help the guarantee of rights.
\end{abstract}

Keywords: Local Power. Public policy. Human Rights. ICMS Ecological. Public Money.

\footnotetext{
${ }^{1}$ Mestranda pela Programa de Pós-gradução em Direito da Universidade Federal do Pará - PPGD UFPA. E-mail: feio.luiza@gmail.com

2 Doutora e Professora da Universidade Federal do Pará. E-mail: lise@cesupa.br
} 


\section{INTRODUÇÃO}

O Poder Local a partir dos debates internacionais está ganhando força como efetivador e garantidor de Direitos Humanos quando fora reconhecido seu papel como implementador de políticas públicas de cunho participativo e transparente.

A estratégia internacional de gestão pública das Nações Unidas (ONU) era promover aplicação de ações governamentais a partir do ente federativo que estivesse mais próximo da população e das mediações políticas, isto é, que pudesse realizar debates mais intensos por meio de diversos atores em determinado espaço territorial consideravelmente pequeno.

Assim, surgiu o prestígio e a importância extrema dos Municípios em realizar políticas públicas que pudessem incluir todas as diversidades e necessidades dos cidadãos, e que cada problema surgido no seio do espaço urbano pudesse ser solucionado de forma multifacetada, a compreender os efeitos de cada ação governamental para o indivíduo em seu particular.

Entretanto, não se pode realizar política pública quando as verbas orçamentárias locais estão sendo utilizadas para um grupo específico da população a partir dos interesses de quem detém o poder político, ou quando estão sendo utilizadas a partir da má gestão, direcionando parte dos valores em gastos com pessoal, por exemplo.

Neste viés, o presente trabalho se propôs a pesquisar qual o papel do Poder Local, isto é, dos Municípios na concretização dos Direitos Humanos a partir do instrumento da política do ICMS Ecológico, com a finalidade de compreender a nova dinâmica do poder local na gestão pública.

Desse modo, o presente trabalho busca encontrar as novas competências do poder local, a partir de um corte analítico no orçamento municipal, isto é, no repasse obrigatório da arrecadação do imposto estadual sobre circulação de mercadorias e serviços, a partir de critérios socioambientais da política pública do ICMS Ecológico.

Já que, a pesquisa se realiza na necessidade de reconhecer que o repasse obrigatório é direito adquirido do Poder Local, como define a própria Constituição Federal de 1988, entretanto, esta verba pública deve estar atrelada ao ordenamento e princípio da própria administração, não podendo ser utilizado a partir do poder discricionário do gestor público.

Portanto, a verba pública que está no fundo municipal é ferramenta fundamental para o desenvolvimento da política urbana, que objetiva ordenar o pleno desenvolvimento das funções sociais da cidade e garantir o bem-estar de seus habitantes, conforme Art. 182 CF/88. 
Assim como, com a intenção de seguir as diretrizes e ordenamento da Lei Orgânica e do Plano Diretor, os quais definem os critérios sustentáveis que devem ser almejados para a melhoria das condições de vida e da preservação ambiental.

Nesta perspectiva, o trabalho fora dividido em três partes. Na primeira será apresentada a transformação de concepção do papel dos Municípios após os debates internacionais e a sua nova função na gestão pública, como principal promotor dos Direitos Humanos a partir de políticas públicas locais.

Na segunda parte do trabalho é apresentado o caso do ICMS Ecológico e explicado a repartição de receita orçamentária a partir dos critérios socioambientais, como delimitador de comportamento, isto é, qual conduta o poder público local poderá apresentar após o repasse da verba pública oriunda da arrecadação do ICMS e seus critérios sustentáveis.

Havendo duas condutas notórias: a primeira, que o poder público local continue seguindo a gestão tradicional e direcionando a verba pública, prioritariamente, com gastos institucionais, para manter a máquina pública, como os gastos com pessoal.

E, a segunda conduta indica seguir a nova estratégia de gestão pública local a partir das concepções da sustentabilidade, principalmente, instituída no Plano Diretor Municipal, que viabiliza o desenvolvimento das funções sociais da cidade e promove a proteção do meio ambiente equilibrado.

Nesta concepção, é que se desenvolve a terceira parte do presente trabalho, com a finalidade de apresentar a importância da continuidade da política pública do ICMS Ecológico no âmbito do poder local, em razão, que os gastos com a verba pública devam estar conforme as previsões do Plano Diretor, a fim que se promova acessibilidade e bem-estar para toda a comunidade local.

\section{A EFETIVAÇÃO DOS DIREITOS HUMANOS PELO PODER LOCAL}

Atualmente é notória a presença do Ordenamento Jurídico Internacional que valore os Direitos Humanos a partir de um conjunto de convenções; tratados; pactos como dos direitos civis e políticos, e econômicos, sociais e culturais; organismos internacionais, como a Comissão dos Direitos Humanos da ONU e a Corte Interamericana de Direitos Humanos, sendo todos voltados para proteção desses direitos.

Entretanto, para efetivação dos Direitos Humanos, as normativas tanto aconselhadas quanto impostas pelo âmbito internacional são concretizadas efetivamente no âmbito local. 
Assim, surgiu a importância do papel dos Municípios para a garantia dos Direitos Humanos a partir da continuação do trabalho realizado por entes e organizações de âmbito nacional e internacional.

O exemplo inegável do papel local, segundo Saule Junior (2001, p. 18), foi a Conferência das Nações Unidas sobre assentamentos, em 1996, realizada na cidade de Istambul, denominada de Habitat II, em que reconheceu o poder local competente para promover políticas públicas em prol da garantia de direitos como o direito a moradia.

A partir da concepção sustentável das cidades perpassando pela inibição da exclusão social, degradação ambiental, e, principalmente possibilitando acessibilidade a todos, é que surgiram diversos programas de cunho local, como Agenda 21 Local ou a Agenda Habitat, com a finalidade de orientar e estimular ações locais.

No que se refere à Agenda 21 Local (2011, p. 9), esta fora elaborada na fase preparatória da Conferência das Nações Unidas para o Meio Ambiente e Desenvolvimento (RIO-92) a partir da necessidade da Agenda Global incentivar o poder local, como os municípios, a promover a elaboração de seus objetivos sustentáveis.

Sendo esses mesmos objetivos descritos na Cartilha Passo a passo da Agenda 21 Local (2005, p. 45), como "estabelecer uma abordagem multissetorial e sistêmica entre as dimensões econômica, social, ambiental e institucional", assim como, "promover o planejamento estratégico participativo por ser projeto de toda a sociedade brasileira".

Desse modo, a essência dos programas de desenvolvimento local fora elaborada em debates internacionais, a reconhecerem a importância do papel local na efetivação de direitos que garantam vida digna para todos, a partir do trabalho de cooperação com o governo internacional, nacional, local, empresas privadas e sociedade, que participará das tomadas de decisões de sua própria comunidade.

Assim sendo, para efetivação dos Direitos Humanos é necessário que o planejamento e/ou políticas públicas idealizadas nas maiores instâncias internacionais sejam efetivadas no âmbito local a partir da descentralização efetiva das responsabilidades entre os entes, isto é, garantindo e reforçando as competências dos municípios para atuar no que lhe couber e houver necessidade.

Essa descentralização das competências ocorreria por meio da revisão das legislações vigentes e, principalmente, garantindo o entendimento constitucional que os municípios fazem parte, após a Constituição de 1988, da federação e são dotados de autonomia para gerirem seu espaço territorial. 
Portanto, em razão da autonomia, a gestão dos municípios não seria imposta pelos outros entes da federação, apenas orientados a partir do apoio e incentivo destes demais atores políticos que contribuiriam com experiência, tecnologia e mecanismos de gestão administrativa.

A partir do propósito de capacitar e habilitar os governos locais, assim como, fortalecer os grupos mobilizados pela própria comunidade, como sindicatos, organizações não governamentais e comunitárias para o planejamento e gestão da vida pública e social dos municípios que promovem políticas públicas.

Essas políticas públicas serão pensadas a partir da observância contínua dos princípios: da responsabilidade a partir do que se está gerindo; da transparência com os recursos orçamentários utilizados, e principalmente, do princípio da participação, a reforçar a capacidade dos governos locais através do desenvolvimento da educação à cidadania e mecanismos, como a consulta pública.

Neste contexto, que Bucci (2006, p. 259) entende que a política é mais ampla que o plano de trabalho, por ser compreendida como a escolha dos meios para a realização dos objetivos do governo com a participação dos atores políticos de cunho público e privado que dialogam com a comunidade.

Assim, a política pública está além de meras escolhas pelo governo em exercer suas capacidades de decisão, pois, não compete ao mesmo, tamanha responsabilidade, mas sim, da participação de diversos atores envolvidos da vida comunitária e política da sociedade local.

Neste viés, que Bucci (2006, p. 271) afirma que o Poder Executivo tem exercido função normativa em regulamentar política pública, a partir do fenômeno da capacidade normativa de conjuntura, com o propósito da interação dos poderes, e, sobretudo entre os entes, mas sempre respeitando a autonomia de cada um, para que haja as melhores condições de aplicação de políticas públicas para promoção dos Direitos Humanos.

Assim, partindo da premissa que o Município é ente da federação, o mesmo tem competência política e econômica para promover políticas públicas que concretizem os Direitos Humanos ou que garantam bens que são instrumentos para promoção destes direitos, como a moradia, saúde, educação, saneamento básico entre outros.

E, uma das ferramentas basilares para esta promoção de direitos no âmbito local são as Leis Orgânicas, os Planos Diretores e o Estatuto da Cidade a partir da construção multifacetada e de diversas vozes que dialogam em prol das melhores condições para todos, assim como, para que se efetivem os direitos basilares para vida digna. 
Visto que, tanto as Leis Orgânicas, quanto os Planos Diretores necessitam ser gerais em sua abrangência, abarcando diversos setores e apreendendo concepções da sustentabilidade, a partir da construção do espaço urbano que promova o bem-estar para todos.

Logo, as ações governamentais devem obedecer a vários anseios dos diversos atores políticos, como exemplo, a necessidade da recuperação do centro da cidade ou de determinado prédio histórico, entretanto, que não deva ser pensado como apenas em mero estímulo na economia, a partir do turismo, mas também, a partir do bem-estar promovido na própria comunidade como mais uma opção de lazer.

Assim como, é necessário que estas ações governamentais no âmbito local considerem a diversidade cultural, de classes sociais, de gênero entre outros fatores de divisão de pensamento e necessidades, devendo ter políticas públicas para todos, com o intuito de garantir qualidade de vida para aqueles que habitam seu espaço territorial.

Portanto, quando se pensa em mobilidade urbana, por exemplo, é necessário pensar em diversos fatores, como acessibilidade para os deficientes físicos ou na locomoção de crianças pequenas em carrinhos de passeio, como também, pensar naqueles que optem por andar a pé, ou de bicicleta, devendo ter mais ciclovias no espaço urbano, ou, então, aqueles que desejem ir ao trabalho de carro particular, mas sem que haja o aumento da poluição do ar, e consequentemente o aumento de doenças respiratórias.

Desse modo, percebe-se a interação entre atores políticos e sociais, e principalmente a complexidade na formulação de uma política pública que garantam os Direitos Humanos para todos os cidadãos, mesmo reconhecendo a existência de conflitos de interesses na sociedade.

Assim sendo, é papel crucial do poder local/municipal executar estas políticas públicas por estar mais próximo das problemáticas, da diversidade e dos conflitos de interesses, a ser considerado o mais apto em efetivar direitos e negociar estratégias de gestão administrativa a partir de diversas concepções.

Neste viés, é importante que os Municípios adéquem seus fins sustentáveis para o recurso disponibilizado em seus fundos, seja de repasse da arrecadação de impostos dos estados, seja de suas próprias cobranças tributárias, mas que todas estas verbas públicas devam contribuir para uma cidade sustentável em prol do bem-estar social ou da própria preservação do meio ambiente.

Logo, a partir dessa perspectiva do papel primordial do poder local para efetivação dos Direitos Humanos, elegeu-se a política pública do ICMS Ecológico a fim de analisar suas 
formas de efetivação e aplicabilidade da gestão participativa do poder público e que promova a qualidade de vida para todos.

\section{A POLÍTICA PÚBLICA DO ICMS ECOLÓGICO}

Para melhor entendimento da política pública do ICMS Ecológico é esclarecido da seguinte forma, a Constituição Federal de 1988, em seu Art. 158 define quais receitas tributárias devem ser repartidas entre os entes federativos.

E dentre elas, mais precisamente no inciso IV, é estabelecido que $25 \%$ do produto da arrecadação do imposto estadual sobre operações relativas à circulação de mercadorias e sobre prestações de serviços de transporte interestadual e intermunicipal e de comunicação (ICMS) devam ser repassadas aos municípios que façam parte do território estadual.

Desses vinte e cinco por cento, três quartos, no mínimo, é direcionado para o valor adicionado nas operações relativas à circulação de mercadorias e das prestações de serviços, realizadas em seus territórios (parágrafo único, inciso I, do Art. $158 \mathrm{CF} / 88$ ).

E, até um quarto é facultado à administração pública estadual gerir como lhe couber, sendo atualmente convertido em condicionantes de repasse da arrecadação do ICMS em favor de melhorias ao meio ambiente e ao bem-estar social (parágrafo único, inciso II, do Art. 158 $\mathrm{CF} / 88)$.

Entretanto, nesta política pública não basta ter critérios de repasse, seja por meio da preservação ambiental ou de índices sociais como educação, saúde e saneamento utilizados por parte dos Estados do Brasil.

Também, é necessária a continuidade dessa mesma política pelo poder local, pois, a quantia que entra nos fundos municipais deve ser bem gerida pelo Poder Local, e principalmente usadas na promoção de ações governamentais a fim de promover a vida digna para a comunidade, como prevê a Lei Orgânica, Plano Diretor e o Estatuto da Cidade, a se pautarem nas concepções sustentáveis do espaço urbano.

Assim, a edição da legislação municipal se faz essencial, conforme afirma João da Matta (2016, p. 4) para garantir que a verba pública recebida via repasse do ICMS Ecológico sejam utilizadas em ações administrativas que visem à preservação do meio ambiente e condições de vida digna.

Logo, o Município possui função importante na operalização desta política do ICMS Ecológico, indo além de mero fiscalizador, quando também garante que os critérios de repasse 
sejam obedecidos em seu território, assim como, que os recursos recebidos sejam direcionados para o mesmo fim sustentável, o qual deve pairar as ações governamentais.

Nesse viés, explica Tupiassu (2006, p. 93) que a implementação de políticas fiscais de cunho ambiental reflete na otimização nas políticas regulatórias tradicionalmente adotadas, pois, além de proporcionar o incentivo à preservação ambiental também garantem maiores receitas para os municípios, possibilitando trabalharem de forma mais eficaz em prol da comunidade.

Portanto, a origem do ICMS Ecológico é resultado da busca de alternativa para o financiamento público das condições sustentáveis dos espaços urbanos, como afirma Scaff (2004, p. 172), em que as condições de preservação ao meio ambiente e a garantia da qualidade de vida são fortes empecilhos para o desenvolvimento das atividades econômicas clássicas.

Entretanto, mesmo com o efeito estimulante da política pública do ICMS Ecológico, é necessário que haja a fiscalização pela própria comunidade, com o intuito de acompanhar a utilização dos valores recebidos, e principalmente o exame da veracidade das informações prestadas para fins de repasse de verba pública da arrecadação desta política.

Deste modo, a política do ICMS Ecológico além de ação estadual, por ser instituída por lei estadual, é, também, ação governamental de cunho local promovida pelo município, por ser essencial a sua tarefa de continuidade de efetivação dessa política, desde simples fiscalização até a promoção de outras políticas públicas a partir da receita arrecada com o próprio ICMS Ecológico.

Logo, o papel da gestão municipal e sua função promotora de Direitos Humanos também podem ser encontrados neste caso concreto, a partir dos princípios basilares da política pública de cunho sustentável, já mencionados na "Sessão 2", como da transparência, a fim de facilitar a fiscalização dos investimentos do repasse da arrecadação do ICMS.

Como também, da participação popular, em que a comunidade terá voz e contribuirá com a tomada de decisão política, conjuntamente com o poder público e entidades privadas, facilitando o diálogo entre estes atores políticos a partir do desenvolvimento da cidadania e de mecanismos de consulta pública.

E, finalmente a partir da descentralização das responsabilidades em promover bemestar para toda a comunidade, por meio do estímulo das capacidades dos governos locais, através da interação de outros entes que os auxiliem com técnicas metodológicas para efetivação de políticas públicas para promoção dos Direitos Humanos. 


\section{A IMPORTÂNCIA DA CONTINUIDADE DA POLÍTICA PÚBLICA DO ICMS ECOLÓGICO PELO PODER LOCAL}

Após breve explanação da importância do papel dos Municípios na promoção dos Direitos Humanos, assim como, da contextualização da política pública do ICMS Ecológico, já é possível desenhar esta política pública e a sua necessidade de continuidade a partir de ações governamentais no âmbito municipal.

Deste modo, o que é almejado são as ações dos munícipios após o recebimento das verbas públicas do repasse referente à arrecadação do ICMS Ecológico, a fim que invistam em projetos que garantam o espaço urbano sustentável a partir da preservação do meio ambiente e da qualidade de vida.

Entretanto, nem sempre, ou melhor, quase sempre a boa vontade do gestor em contribuir com a vida digna para seus cidadãos não aflora no cotidiano do município que possui outras dívidas, que pode ser consideradas emergentes do ponto de vista do próprio gestor, como os gastos com funcionários, ofuscando, assim o plano do espaço sustentável.

\subsection{A questão com gastos de pessoal}

Nessa perspectiva Torres (2011, p. 182) afirma que um dos aspectos importantes na gestão orçamentária é o controle de despesa com o pessoal, disposto no Art. 169 da Constituição Federal de 1988, em que prevê que estes não poderão ultrapassar ao limite previsto em lei, isto é, na Lei de Responsabilidade Fiscal.

Esta Lei trouxe inúmeras previsões que no âmbito geral estabeleceu limitações de gastos para cada ente da federação, conforme Art. 19 da LRF; entre os Poderes Executivo, Legislativo, Judiciário e Ministério público previsto no Art. 20; assim como, nos Art. 21, 22 e 23, que estabeleceram normas gerais para o controle total de pessoal.

Neste mesmo viés, Afonso, Carvalho e Castro (2010, p. 29) apontam que no Relatório de Gestão Fiscal apresentado no final de cada quadrimestre é permitido o controle de alguns limites básicos na LRF, expressos em proporção da receita corrente líquida, e um deles é a 
própria despesa com pessoal tanto por Poder ou órgão, ou então, consolidada por todo o governo.

Deste modo, é notório o esforço que a lei faz para inibir um dos maiores gastos do poder público, isto é, com remuneração de pessoal, a fim de corrigir os vestígios da gestão pública burocrática, que causam déficits no rendimento da prestação de serviços públicos para comunidade.

Havendo assim a necessidade da existência de outra gestão pública que contribua com a efetivação da participação popular e do bem-estar social de todos que participem da comunidade, a fim de objetivar maior eficiência na promoção dos objetivos da construção de espaços urbanos sustentáveis.

\subsection{Plano Diretor e as competências locais}

Assim, as ações governamentais devem utilizar a verba pública de forma equitativa às políticas que promovam a cidade sustentável, não se limitando em pagar dívidas e gastos com pessoal, sem ao menos dar satisfação à própria comunidade das decisões do gestor público.

Desse modo, como já mencionado na "sessão 2" é necessário o incentivo das competências do poder local que promovam políticas públicas, isto é, que vão além do gestor que paga dívidas e administra a máquina pública, indo de encontra também com o gestor que promove bemestar para comunidade.

Neste aspecto, a competência estabelecida na própria Constituição Federal parece conflitante como afirma o Centro de Apoio Operacional do Meio Ambiente (2011, p. 01), em razão dos municípios não figurar como ente competente no Art. 24, caput da CF/88.

Entretanto, cabe aos municípios legislar assuntos de interesse local e suplementar a legislação federal e estadual no que couber, conforme previsão do Art. 30, incisos I e II da $\mathrm{CF} / 88$.

Cumpre assim mencionar a importância do Plano Diretor dos municípios, previsto no Art. $182, \S 2^{\circ}$ da $\mathrm{CF} / 88$ ao afirmar que a "propriedade urbana cumpre sua função social quando atende às exigências fundamentais de ordenação da cidade expressas no Plano Diretor".

Visto que, neste capítulo da Constituição Federal, que versa sobre a política de desenvolvimento urbano, como afirma Daniella Dias (2012, p. 16-21), tem como objetivo 
ordenar o pleno desenvolvimento das funções sociais da cidade e garantir bem-estar para seus habitantes.

Logo, a Constituição Federal vigente ao criar este capítulo específico sobre política urbana, produziu inovadoras diretrizes para o sistema jurídico, a garantir aos cidadãos o acesso a espaços urbanos sustentáveis e justos.

Neste viés, o dispositivo constitucional, em poucas palavras, expressa um complexo sistema normativo de regras e princípios que constroem uma nova concepção de justiça socioambiental por meio da releitura de princípios constitucionais, como o princípio da função social da propriedade, o princípio da igualdade, da dignidade humana, do direito à qualidade de vida e do meio ambiente sadio.

Deste modo, todos estes princípios constitucionais devem ser interpretados a partir da interação do próprio disposto do Art. 182 da CF/88, que define a política do desenvolvimento urbano, que deverá ser executada pelo poder local dos municípios, a partir do objetivo de ordenar o pleno desenvolvimento das funções sociais da cidade e garantir a vida digna para todos que habitem seu espaço territorial.

Portanto, percebe-se a obrigatoriedade do poder local no âmbito municipal em promover políticas públicas nos seus espaços urbanos a fim de cumprir as diretrizes e princípios estabelecidos na própria Carta Magna, a partir de uma responsabilidade de todos os entes da federação, mas que recai com mais força no poder local.

Tal responsabilidade mais atinente aos municípios é consequência gradativa da delegação de atribuições, como já dito na "sessão 2", a partir da alterações com a nova CF/88, que previu autonomia política, administrativa e financeira para estes entes da federação a partir do âmbito local.

Já que na perspectiva do Federalismo Cooperativo, a União, por sua competência para tratar de assuntos federais, estabeleceu normas gerais da política de desenvolvimento urbano nacional, normas estas que os entes municipais deverão obedecer e considerar para que sejam criadas as Leis Orgânicas e os Planos Diretores municipais.

Importante salientar que todos os entes federativos têm competência para tratar da política urbana, conforme o Art. $24 \mathrm{da} \mathrm{CF} / 88$, entretanto, no caso dos municípios, este tem a competência de suplementar o que for disposto em norma federal e estadual, por ter competência legislativa concorrente, de acordo com o Art. 30, II da CF/88.

E, dentre as medidas dispostas no artigo referente às competências comuns do Art. 23 da $\mathrm{CF} / 88$ dos entes da federação, destaca-se aquelas que devem ser atendidas com mais 
urgência para que se produzam espaços urbanos sustentáveis, como exemplo, a promoção de programas de construção de moradias e a melhoria das condições de saneamento básico.

Com a finalidade, de tais programas serem executados de forma paralela ao combate das causas de pobreza, como a inibição do desemprego e garantia da qualidade educacional, assim como, dos fatores de marginalização, a fim de promover a integração sociopolítica de grupos sociais mais vulneráveis, a partir da concepção de proteção ambiental e cultural da comunidade que habita o território municipal.

Em razão, da garantia do bem-estar, disposto no caput do Art. 182 da CF/88, ser efetivada a partir da prestação de serviços públicos para que todos possam usufruir de seus direitos, como habitar, circular, trabalhar e aproveitar o lazer nos espaços municipais.

Relevante ressaltar que este desenvolvimento das funções urbanísticas municipais em prol do bem-estar de todos os cidadãos, se encontra descrito nos planos diretores dos municípios, a ser considerado instrumento eficaz de efetivação de Direitos Humanos, quando suas normas estão fundamentadas nas concepções de cidadania e dignidade da pessoa humana.

Assim, para se alcançar os objetivos da implantação das diretrizes sustentáveis do Plano Diretor Municipal se pressupõe, primeiramente, a concretização de políticas públicas no espaço urbano quando a ação estatal é ausente em comunidades que não são beneficiadas pela promoção do bem-estar, a residirem em áreas degradadas e de difícil acesso, por exemplo.

Portanto, a qualidade de vida como critério para o bem-estar de todos necessita, para sua efetivação, de espaços dignos à sobrevivência humana, em que o meio ambiente seja preservado, assim como, que haja ações de gerenciamento de resíduos sólidos e água tratada para todos, sem qualquer distinção.

Visto que o princípio da igualdade, importante para o desenvolvimento urbano municipal, compreende o isonômico tratamento dos municípios, por meio da atribuição de iguais direitos às funções sociais da cidade, e principalmente, adequando políticas públicas, promovidas no âmbito local, a partir das necessidades de cada indivíduo e de suas particularidades, sejam sociais, étnicas, de gênero, ou então físicas.

A carecer, portanto, do estabelecimento de políticas públicas urbanas que proporcionem o acesso a empregos, a satisfação das necessidades básicas, isto é, que a comunidade goze de seus direitos fundamentais, e consequentemente, seja erradicada a pobreza e marginalidade sociais. 
Deste modo, o Plano Diretor, enquanto método técnico que viabiliza o desenvolvimento das funções sociais da cidade tornou-se obrigatório para as cidades que tenham mais de 20.000 (vinte mil) habitantes a partir da necessidade de planificação de políticas públicas urbanas condicentes com a realidade da comunidade.

E, que principalmente, se tornem exigíveis pelos cidadãos e passíveis de fiscalização, conforme o princípio da transparência na elaboração de políticas e na gestão da administração pública, para que, assim, se atrele as ações do Prefeito Municipal às diretrizes do Plano Diretor.

Entretanto, no que se refere à falta desse plano para aqueles que não têm a obrigatoriedade de elaborá-lo, deve ser ressaltado, que a ausência de elaboração tem efeitos negativos para o poder local, como a impossibilidade de utilizar o parcelamento ou edificações compulsórias de terrenos urbanos, por exemplo.

Assim, é imprescindível que todos os municípios elaborem seu Plano Diretor para que possam realizar e desenvolver política urbana a partir do desenvolvimento das funções sociais da cidade das concepções sustentáveis.

Já que, qualquer norma que intente estabelecer padrões e critérios municipais para realização da política urbana e que não se expressem no plano diretor, não terá validade alguma para efeitos de ações municipais e, principalmente legais.

\subsection{O Estatuto da Cidade e o interesse social da comunidade}

Nesse viés, diante da importância do papel do poder local para promoção da política de desenvolvimento urbano, fora elaborada a ferramenta primordial para sua concretização que é o Estatuto da Cidade, isto é, Lei Federal nº 10.257/2001.

Por tratar de legislação que dispõe o conjunto de diretrizes gerais para execução de política pública urbana, assim como, prevê orientações para as ações dos governos municipais, conforme Dias (2012, p. 43), portanto, são os métodos de aplicação ao caso concreto para promoção de cidades sustentáveis.

Assim, o Estatuto da Cidade é o instrumento que incorpora maior densidade ao dispositivo constitucional da política urbana no Art. 182, ao apresentar o modelo jurídico e principiológico que os municípios devem percorrer durante sua gestão administrativa.

Com a finalidade primordial em garantir as diretrizes sociais, contidas no Art. $2^{\circ}$ do Estatuto da Cidade, oriundas de ações e estratégias da política urbana, tanto as que beneficiam 
a coletividade, como a prestação dos serviços públicos, quanto as que permitem a participação democrática no processo de urbanização, como afirma Carvalho Filho (2013, p. 44).

Visto que, o direito à cidade sustentável previsto no inciso I das diretrizes, já perpassa pela concepção de alcançar os anseios da população, isto é, do processo de urbanização ser pensado em prol do bem-estar de todos, com áreas de moradia e lazer adequados para a sobrevivência, e principalmente, vivência em sociedade.

Entretanto, ao mesmo tempo em que o Estatuto considera a necessidade de serviço público, também, reconhece a importância da participação popular na formulação, execução e acompanhamento de planos, programas e projetos de desenvolvimento urbano (inciso II, Art. $2^{\circ}$ do Estatuto da Cidade), a partir de instrumentos democráticos, como a própria audiência prévia às populações prevista no inciso XIII.

Neste viés, percebe-se que o espaço urbano sustentável depende de vários atores interagindo, e principalmente dialogando, devendo, assim, ser exercido o Estatuto a partir da cooperação entre os governos, iniciativa privada e demais setores da sociedade no processo de urbanização, conforme o inciso III, do Art. $2^{\circ}$ do próprio Estatuto da Cidade.

Desse modo, tanto o Plano Diretor, quanto o próprio Estatuto da Cidade, na sua total abrangência, são instrumentos que norteiam o papel inovador do poder local a partir de diretrizes que devem ser aplicadas pelo município para que se garanta vida digna para todos a partir das necessidades particulares de cada ser.

Logo, percebe-se a notória ligação entre os fundos municipais alimentados por uma parcela do repasse de arrecadação do imposto de circulação de mercadorias a partir de critérios socioambientais, isto é, da política do ICMS Ecológico, com as diretrizes que são estabelecidas nestes ordenamentos jurídicos.

Em razão, que o fundo não deve ser usado a partir das conveniências do gestor público, mas para que sejam propostos espaços urbanos sustentáveis, que garantam os Direitos Humanos dos cidadãos, sejam eles de cunho social, por meio da garantia de bens como o saneamento básico, o acesso à moradia, educação e lazer.

Sejam de cunho cultural, em que os espaços da memória étnica sejam preservados em prol das raízes e concepções de diversas ideologias e manifestações de liberdade entre os indivíduos.

Ou de cunho político a partir da construção da cidadania, através do incentivo da participar popular e da educação política dos cidadãos que tem toda a liberdade de fazerem parte da tomada de decisões e das ações governamentais dos municípios. 


\section{CONSIDERAÇÕES FINAIS}

Portanto, o presente trabalho objetivou apresentar o papel do poder municipal na efetivação de políticas públicas que contribuam para promoção de Direito Humanos, por meio das verbas públicas contidas nos fundos municipais que são originados, em parcela considerável, pelo repasse da arrecadação do imposto de circulação de mercadorias a partir dos critérios socioambientais, isto é, da política do ICMS Ecológico.

Assim, tais políticas elaboradas pelo poder municipal deverão ser a continuidade do ICMS Ecológico, pois, não basta o estímulo de repasse após o êxito em critérios socioambientais estipulados em lei estadual, mas é necessário planejar outros mecanismos de aplicação desta verba conseguida com o repasse.

Ou seja, é necessário, conforme as diretrizes do Plano Diretor Municipal, do Estatuto da Cidade, e da própria Lei Orgânica do Município, que haja a implementação da concepção sustentável nos espaços urbanos com os valores repassados pelo ICMS Ecológico, e que foram direcionados para cada município.

Importante ressaltar, que não se deseja vincular a receita do ICMS Ecológico nas diretrizes estabelecidas pelo Estado, pois, realmente não compete a estes definir o orçamento de outro ente federativo, como o município, mas sim, de estimular condutas que satisfaçam os padrões sustentáveis, como a preservação do meio ambiente e a promoção da qualidade de vida para quem habite este mesmo ambiente territorial municipal.

Logo, fica a critério da própria gestão municipal atender os critérios ou não da política pública do ICMS Ecológico a partir das concepções sustentáveis, por meio de índices socioambientais, como a qualidade da educação, índices de mortalidade infantil e a existência do gerenciamento de resíduos sólidos.

Assim, se forem atendidos tais critérios, o município, ao mesmo tempo, e na mesma ação governamental terá promovido as diretrizes dos Planos Diretores e conseguido mais verba pública para sua gestão, a fim de garantir outras políticas públicas que promovam o bem-estar de todos.

Nota-se que é um ciclo participativo e interativo que estimula cada vez mais políticas públicas em prol dos cidadãos, logo, este é o ideal de efetivação de Direitos Humanos criado por gestores e pesquisadores, para que em cada repasse seja repensado novo plano de trabalhos sustentáveis. 
Entretanto, a prática diverge da idealização da política pública do ICMS Ecológico, pois, ao se conseguir o repasse das verbas, estas são direcionadas para fins públicos pouco eficientes para promoção da sustentabilidade propriamente dita, sendo direcionado, como já mencionado, para pagamento com gastos com pessoal, por exemplo.

Deste modo, retorna-se ao debate da participação popular, pois, a partir de mecanismos viáveis de transparência das ações governamentais é possível que a comunidade participe na elaboração de políticas públicas que promovam vida digna, e principalmente, fiscalizem as condutas dos gestores municipais que estão atrelados aos Planos Diretores que são fincados pelas diretrizes da sustentabilidade.

\section{REFERÊNCIAS BIBLIOGRÁFICAS}

AFONSO, José Roberto; CARVALHO, Guilherme Luís Nilson Pinto de; CASTRO, Kleber Pacheco de. Desempenho comparado dos principais governos brasileiros depois de dez anos de LRF. In: Revista Técnica do Tribunal de Contas. Belo Horizonte: Fórum, 2010.

BRASIL. Agenda 21 Local: resultados selecionados. Brasília: Ministério do Meio Ambiente, 2011.

BRASIL. Passo a passo da Agenda 21 Local. Brasília: Ministério do Meio Ambiente, 2005. BUCCI, Maria Paula Dallari. Direito Administrativo e Políticas Públicas. São Paulo: Saraiva, 2006.

CARVAlHO FILHO, José dos Santos. Comentários ao Estatuto da Cidade. São Paulo: Atlas, 2013.

CENTRO DE APOIO OPERACIONAL DO MEIO AMBIENTE. Os Municípios e a Gestão Ambiental. In: Considerações produzidas pela Assessoria Jurídica do Centro. Ministério Público: Goiás, 2011.

DIAS, Daniella Maria Dos Santos. Planejamento e desenvolvimento urbano no sistema jurídico brasileiro. Curitiba: Juruá, 2012.

MATA, João da. O Município e o ICMS Ecológico: recursos para o meio ambiente. Programa de qualificação gestão ambiental. Mato Grosso: Informativo, 2016. Disponível em: http://www.amazonia-ibam.org.br/biblioteca/publicacao/detalhe/joao-da-matta,-analista-emdireito-ambiental---pqga/49.

ONU. Conferência sobre Assentamentos Humanos. Declaração de Istambul e Agenda Habitat. Habitat II, Istambul, 1996. 
SAUle JUNIOR, Nelson. Políticas Públicas Locais: Município e Direitos Humanos. In: BUCCI, Maria Paula Dallari. Direitos Humanos e Políticas Públicas. São Paulo: Pólis, 2001, p. $17-31$.

SCAFF, Fernando Facury; TUPIASSU, L. V. C. Tributação e Políticas Públicas: O ICMS Ecológico. Verba Juris (UFPB), v. 3, p. 154-190, 2004.

TORRES, Ricardo Lobo. Curso de Direito Financeiro e Tributário. $18^{a}$ edição. Rio de Janeiro: Renovar, 2011.

TUPIASSU, Lise Vieira da Costa. Tributação Ambiental: a utilização de instrumentos econômicos e fiscais na implementação do direito ao meio ambiente saudável. Rio de Janeiro: Renovar, 2006. 